\title{
REPORT FROM THE 37TH INTERNATIONAL CONFERENCE OF THE STRESS AND ANXIETY RESEARCH SOCIETY (STAR): "STRESS AND ANXIETY IN A CHANGING SOCIETY", ZAGREB (CROATIA), JULY 6-8, 2016
}

\author{
Monika M. MAŁKIEWICZ1 , Jan F. TERELAK² \\ ${ }^{1}$ Cardinal Stefan Wyszynski University in Warsaw, Institute of Psychology, Warsaw, Poland \\ ${ }^{2}$ Military Institute of Aviation Medicine in Warsaw, Warsaw, Poland
}

Source of support: Own sources

Author's address: M.M. Małkiewicz, Cardinal Stefan Wyszynski University in Warsaw, Institute of Psychology, Dewajtis 5 Street, 00-001 Warsaw, Poland, e-mail:m.malkiewicz@uksw.edu.pl

The 37th International Conference organized by the Stress and Anxiety Research Society (STAR) took place on 6-8th of July in Zagreb, Croatia.

The aim of the annual STAR conferences is the presentation of and discussion on the new theoretical and practical achievements in the field of stress, anxiety and coping. The conference is attended by international experts and especially by psychologists. The discussed topics often involve current social and political problems. An emphasis is put on presenting research that could contribute to a better understanding of human functioning under difficult conditions, which could have practical implications. The topic of this year's conference was Stress and Anxiety in a Changing Society.
Among the speakers, there were scientists from 33 countries; 274 investigators presented their research during 12 symposia, 23 topic series and 2 poster series. Polish scientific centers were represented by 21 active participants of whom the majority presented posters. Three presentations were given as part of the topic series by: M. Kaczmarek, M. Leśnierowska, R. Cieślak (Department of Psychology, University of Social Sciences and Humanities, Warsaw) - "From Neuroticism through Exhaustion and Self-Efficacy Change to Disengagement: New Findings on Job Burnout Development in Firefighters" (co-authors); M. Małkiewicz, J.F. Terelak (Institute of Psychology, Cardinal Stefan Wyszynski University in Warsaw) - "The Role of Hope in Coping: Presentation of Lazarus's Ap-

Full-text PDF: http://www.pjambp.com • Copyright @ 2016 Polish Aviation Medicine Society, ul. Krasińskiego 54/56, 01-755 Warsaw, license WIML •Indexation: Index Copernicus, Polish Ministry of Science and Higher Education 
proach"; P. Stecz (Institute of Psychology, University of Lodz) - "The complexity of coping: An alternative approach to assessing coping - adaptation relationships".

The conference was opened by chair of the Organizing Committee - Prof. Nataša Jokić-Begić, who remarked on the difficult history of Croatia and the whole Balkan region and underscored that potential sources of stress do not cease to exist with the end of war or social and economic crises. She also noted that currently the processes of globalization, development of new technologies, social changes, requiring from us respect towards diversity and human rights of the individual, are all sources of stress and unrest. In her opinion, new challenges can also bring new possibilities, but this is associated with stress and anxiety. Prof. Jokić-Begić encouraged attendees to think of and discuss the changes that are currently occurring regardless of the world regions from which we come. The opening lecture was given by Brian Hughes, and it was called: "Rethinking Stress and Anxiety Research: Good and Bad Science in Psychology". He talked about the quality of scientific work, methodological correctness and an adequate way of drawing conclusions based on research methods applied. He warned from reducing the activities of people to the activity of the cerebral cortex.

Workshops, lectures, oral and poster presentations were intertwined by speeches given by world-famous keynote speakers such as Prof. Ilan H. Meyer (Williams Institute for Sexual Orientation and Gender Identity Law and Public Policy, UCLA's School of Law, USA), Prof. Nazanin Derakhshan (Department of Psychological Sciences, Birkbeck University of London, UK), Prof. Rita Rosner (Clinical and Biological Psychology, Catholic University of Eichstätt-Ingolstadt, Germany) and Prof. Darja Maslić Seršić (Department of Psychology, Faculty of Humanities and Social Sciences at the University of Zagreb, Croatia). Moreover, the conference was also attended by other excellent scientists who gave their presentations as part of the topic series. They included Prof. Krys Kaniasty, Prof. Shulamith Kreitler, Prof. Robin Goodwin and Prof. Moshe Zeidner.

During the first day of the conference, the symposia dealt with post-traumatic stress ("Death on Live: Media Exposure to Trauma and Posttraumatic Reactions") and resistance to stress ("Psychosocial contributors to Wellbeing"). The topic session concentrated on stress in the elderly ("Stress and Coping in Elderly Population"), the impact of stress and anxiety on health ("Stress, Anxiety and Health"), stress in sports psychology ("Stress Research in Sport Psychology"), consequences of experiencing stress associated with disasters and other traumatic events ("Psychological Consequences of Traumatic Events and Disasters", mechanisms of coping with stress ("Coping Strategies and Mechanisms"), and social anxiety ("Social Anxiety").

A major event of the first day of the conference was the speech given by Prof. Ilan H. Meyer (Williams Institute for Sexual Orientation and Gender Identity Law and Public Policy, UCLA's School of Law) on stress in sexual minorities. Prof. Meyer presented a model differentiating LGBT people in terms of health status. He focused on social stressors, stigmatization, prejudices and their impact on health. He also presented the newest research in LGBT populations and analyzed the influence of stigmatization of minorities on the legislation in selected countries (Russia, Uganda).

During the second day of the conference, 7 symposia and 10 topic series took place. The topics of the symposia included: "Psychological Dimensions of Economic Precarity", "Aging in the Flames of War and Terrorism", "Minority Stress Processes and Health in Lesbians, Gay Men and Bisexuals", "Minority Stress and Mental Health in Transgender Individuals", "Coping with Political Violence: Insights from Cultural and Life Cycles", "Dealing with Stress and Anxiety in Learning Settings", "Psychosomatic Influences on Health". The subjects of the topic series included: "Stress in the Family Context", "Psychosocial Consequences of War", "Occupational Stress: Teachers", "Stress and Resilience in Vulnerable Groups", "Occupational Stress and Burnout in Various Groups of Employees", "School anxiety", "Anxiety, Stress and Coping in the Age of New Media", "Occupational Stress: Helping Professions, Firefighters and the Military", "Academic Stress and Burnout in University and Secondary School Students", ("Parental Stress and Trauma").

During the second day of the conference, the keynote speakers were Prof. Nazanin Derakhshan (Department of Psychological Sciences, Birkbeck University of London, UK) and Prof. Rita Rosner (Clinical and Biological Psychology, Catholic University of Eichstätt-Ingolstadt, Germany).

The subject of Prof. Derekhshan's presentation was "Emotional Vulnerability and the Road to Resilience". Prof. Derekhshan started by remarking that according to WHO in the year 2020 depression and anxiety disorders will be the most common causes of abnormal functioning of people. She said that it is difficult to name a specific cause that increases susceptibility to these disorders; moreover, the ef- 
fectiveness of psychotherapeutic actions is highly limited. Prof. Derekhshan discussed a prefrontal mechanism that controls attention, which can play a role in predicting the occurrence, persistence and recurrence of the above-mentioned disorders (emotional vulnerability). Subsequently, she presented her research in which she determined that owing to a series of interventions, the mechanism of attention can be guided and reinforced in such a way that will promote resilience and psychological flexibility, resulting in a reduced susceptibility to anxiety disorders and depression. Moreover, she focused on the ways of attaining resilience and practical implications of her research.

The title of dr. Rita Rosner's speech was "Prolonged Grief Disorder", which can occur after a traumatic event associated with death of a loved one. She noted that although "complicated grief" or "prolonged grief disorder (PGD)" are included in the ICD-11 classification, they are not found in DSM-5. The main symptoms of the prolonged grief disorder are a strong longing and excessive experiencing of the loss, reactive symptoms of stress such as avoidance of remembering the deceased, emotional numbness, disorders of identity, disorders of social functioning, feelings of alienation or inability to trust other people. Prof. Rosner stated that PGD develops in approximately 5\% of grieving people and PGD can be differentiated from normal grief and post-traumatic stress disorder (PTSD). However, because of some overlapping disorders, the process of differentiating PGD from normal or deep grief can be difficult. Prof. Rosner also reviewed the theories of grief and potential interventions in PGD.

During the third day of the conference, 3 symposia and 7 topic series took place. The topics of the symposia were: "From Cognition to Emotion: Understanding Implications of Transfer Induced Cognitive Change in Emotional Vulnerability and Resilience", "Measuring General Distress: Using the Clinical Outcomes in Routine Evaluation" and "Stress and Intimate Relationships". The topic sessions were as follows: "Psychosomatic Symptoms and Disease", "Stress and Coping: Children, Adolescents and Young Adults", "Measuring Stress, Anxiety and Resilience", "Stress and Coping: Older Adults and Their Caregivers"), "Intra-Family Conflicts and Violence", "Mental Health Problems and Disorders Related to Stress" and "Stress and Anxiety Reducing Interventions".
During the last day of the conference, the key speaker was Prof. Darja Maslić Seršić whose presentation was entitled "Contemporary challenges of coping with unemployment". Prof. Maslić Seršić noted that economic recession increased unemployment levels, which had an impact on occupational life of many people in the majority of European countries. Many employees experienced increased expectations at work, higher levels of job insecurity and even loss of employment. The speaker stated that at times of macroeconomic stagnation the above-mentioned stressors contribute to the individual burden of work that is experienced by workers. Moreover, in countries with high levels of unemployment and stagnation (including Croatia), workers are faced with exceptionally high expectations. Subsequently, Prof. Maslić Seršić discussed and compared the results of recent studies, both cross-sectional and longitudinal, in countries with high unemployment and low job mobility. She also emphasized the role of individual cost of adaptation in the process of mandatory job mobility, i.e. of the situation of being intermittently employed and unemployed based on contracts that do not guarantee stability and safety. The conclusions drawn by Prof. Maslić Seršić referred to the theory of the meaning of work and preservation of resources. The speech ended with recommendations on the psychological interventions for three different groups of the unemployed - people who have lost their job recently, people who are unemployed long-term and young unemployed who are new to the job market.

When summing up this year's STAR conference, it should be noted that in addition to lectures, plenary and topic session, there were 7 workshops that focused on psychotherapeutic skills and giving psychological support to people in difficult situations. Moreover, the workshop on the use of the statistical software $R$ was well attended. During the last day of the conference, new board of STAR was elected, which was announced during the closing ceremony. It was also revealed that the next year's conference will take place in Hong Kong, China. 